\title{
Insurance and medical resource allocation: a literature review
}

\author{
Ying Liu \\ School of insurance, \\ Central University of Finance and Economics, \\ Beijing, China
}

\begin{abstract}
The contribution of the existing research results of insurance and resource allocation in theory and policy proposition has important reference value for the study of the operation mechanism and policy orientation of insurance resource allocation. On the basis of combing the research path of the existing research results, this paper combines the insurance theory with the general economic theory, based on China's national conditions, tries to think and choose new research path with new thinking mode, and systematically and deeply discusses the effective allocation of China's insurance resources.
\end{abstract}

Keywords: Insurance; Resource allocation ;Medical resource.

\section{ECONOMIC EXTERNALITY OF INSURANCE}

Domestic scholars have been studying the relationship between insurance industry and economic development for many years. Most of them use premium income, insurance density, insurance depth and other indicators to measure the development level of insurance industry, and use them as variables to examine the relationship between insurance industry and economic growth.

Arrow (1963) believes that diseases will lead to a decline in income level. In addition to the risk of medical expenditure brought by diseases, diseases themselves are a high cost risk. Therefore, medical insurance can avoid these two kinds of risks and bring great social welfare promotion. If the private medical insurance can not resist all risks, the government should take the responsibility of providing social medical insurance.

It can be seen that in the initial study of medical insurance demand, medical service expenditure as an uncertain expenditure leads to the loss of individual welfare, while the demand for medical insurance lies in the avoidance of expenditure risk. His understanding of the medical insurance price in the early stage has the following deficiencies. First, the value of medical service itself is ignored. As an uncertain expenditure, medical service expenditure is a loss of wealth. However, as emphasized in Grossman's health demand theory (Grossman, 1972), medical service itself is valuable, and medical service expenditure is an investment in health, which in some cases guarantees the continuity of life. Individuals without medical insurance may not get medical services due to expenditure budget constraints when they are ill. If medical insurance expands the expenditure budget constraints of patients and improves the accessibility of medical services, it is also the improvement of individual welfare. Secondly, the price effect of medical insurance is not considered. Medical insurance reduces the price of medical services, and distorted price of medical services will lead to excessive medical expenditure, resulting in the loss of social welfare. Arrow (1963) also recognized that medical insurance can lead to moral hazard of patients, but arrow believed that the form of CO 
insurance medical insurance can reduce moral hazard to the minimum, which is Pareto optimal. De Meza (1983) thought that the demand curve of medical service was different when patients had medical insurance and no medical insurance. When the medical insurance provides medical expenses reimbursement, the patients get a transfer of income, the demand curve of medical services moves out, and the willingness of patients to pay for medical services increases. Pauly (1968) did not consider the increase of willingness to pay caused by the transfer of income, which would also lead to overestimation of the efficiency loss caused by moral hazard.

Chenet al. (2007) examined the impact of Taiwan's universal medical insurance on the health and utilization of medical services for the elderly. The study found that Taiwan's universal medical insurance significantly increased the utilization rate of outpatient and inpatient services for the elderly, and had a more significant impact on the low-income and middleincome groups, reducing the inequality in the utilization of medical services, but had no impact on the health status measured by self-rated health and mortality 。 Lu \& Hsiao (2003) believed that Taiwan's universal medical insurance effectively controlled the rise of medical expenses, and the saved medical expenses were far greater than the cost of implementing universal medical insurance.

The research shows that insurance has a positive correlation with economic growth. For example, sun Qi xiang and Ben Ben (1997) believed that the level of social and economic development restricted the development of insurance industry. In the development process of China's insurance industry, the government's macroeconomic policies and the reform of social and economic system played an important role in the transformation of people's risk awareness. Zhao Shangmei and Li Yong (2009) based on the theory of the relationship between financial development and economic growth, using the two sector model, studied the transmission mechanism of the contribution of insurance industry development to economic growth. It proves that the development of insurance industry not only contributes to economic growth, but also has spillover effect on non insurance sectors. Huang Yingjun and Chen yeting (2012) also believed that the insurance industry, with its unique characteristics, can play a special role in economic growth that other financial sectors cannot. Jin Yichen and Bai Yiduo (2017) analyzed the relationship between insurance and economic growth from the perspective of the three carriages: in terms of consumption, the economic compensation function of insurance can reduce the sustainability of residents, stimulate current or even ahead of consumption; in terms of investment, insurance can collect social idle funds for investment while improving the financial market In the aspect of export, we can use export credit insurance as a special product to realize economic compensation and risk transfer, so as to promote economic growth. Liang Laicun and Hu yangzan (2005) believed that insurance consumption had a pull effect on economic growth, and its pull effect gradually increased.

Luan Cuncun (2004) established a long-term and short-term model between the insurance industry and macro-economic factors. The results show that the insurance growth comes from the expansion of the insurance industry itself, the growth of national disposable income and the reform of the market economic system. Lin Baoqing (1996) thought that under the condition of other external conditions unchanged, the premium income and GNP had a high positive correlation, and the premium income and GNP growth showed a synchronous trend. Yang Xiaokai (19982003) pointed out that the insurance system will definitely promote the division of labor and the progress of production efficiency. If only considering the division of labor in the insurance industry itself, the insurance market will play a greater role in economic growth. Wu Jiangming and Lin Baoqing (2003) pointed out that economic growth has a very important impact on total premium income and property insurance premium income, and 
weighted individual disposable income has a very important impact on life insurance premium income. ZhuoZhi (1999) mainly analyzed the change trend of life insurance depth and insurance density in various countries from 1986 to 1997 and the contribution of life insurance to the money capital market. Xiao Wen and Xie Wenwu (2000) believe that the growth of GDP determines the rapid growth of insurance industry. There is a positive correlation between premium income and GDP. Based on the contribution of service economy to national economy, ZhuoZhi (2000) draws the conclusion that life insurance plays an increasingly important role in China's economic growth. According to Xiao Wen and Xie Wenwu (2001), there is a positive correlation between premium income and GDP. Duan Jiaxi (2003) got the conclusion that when the insurance density increased by one percentage point, the national economy increased by 0.6 and 0.15 percentage points at a logarithmic rate respectively. Feng Wenli and Lin Baoqing (2003) believe that the positive externalities of agricultural insurance are reflected in the two aspects of farmers' consumption (or demand) of agricultural insurance and insurance companies' production (or supply) of agricultural insurance, with the positive externalities of supply and demand. Rao Xiaohui and Zhong Zhengsheng (2005) used the data of China's real GDP and total premium to investigate the dynamic relationship between China's economic growth and the development of the insurance market. The results show that, for China, the development of insurance market is not the cause of economic growth, and economic growth is the cause of the development of insurance market. Hu Hongbing (2007) thinks that GDP has Granger causality to insurance growth in both long-term and short-term. Economic growth affects insurance development by changing the investment and consumption demand of insurance market participants, but insurance growth will not cause economic growth. Ren Yanyan and Xu Xiaoyan (2008) tested the contribution of insurance industry development to economic growth in 31 provinces and cities in China. The results showed that there was a similar causal relationship between insurance industry development and economic growth in China, but the role of economic growth in insurance is far greater than that of insurance in economic growth.

Zhang Fangjie (2004) used the time series data from 1980 to 2002 to analyze and measure the economic factors affecting the development environment of China's insurance industry, including the level of economic development, the degree of marketization, the change of industrial structure, the growth of fixed asset investment, the growth of savings and deposits, the level of national tax, inflation and other factors. In the long run, insurance development has a positive impact on economic growth, household savings and deposit balance; $80 \%$ of the development of insurance industry depends on the internal development of insurance industry, and the external impact on the development of insurance industry only accounts for about $20 \%$. However, the impact of insurance development on residents and macro-economy is relatively high.

\section{ALLOCATION OF MEDICAL RESOURCES}

Since Adam Smith, based on the hypothesis of resource scarcity, the history of western economic theory has been discussing the position and role of market and government in the process of economic and social development. Zheng Lei (2011) thinks that the control and utilization of natural resources, the education level of individuals, the amount of capital, technical resources, the support of national policies, political rights and so on are important factors affecting the income distribution gap in China. Qijiahou (2013) believes that the root of many contradictions and problems in China's society lies in the unreasonable way of social resource allocation. In order to deepen the reform of social resource allocation under the socialist conditions, we must correctly deal with the two value objectives of fairness and efficiency. Market, government, society and other resource allocation subjects should play their roles around their functional space, goal orientation and logic It forms a relatively balanced 
tension relationship between them and restricts any of them to the extreme. Medical insurance can reduce the price of medical services, reduce the economic burden of medical service demanders, and may lead to the rise of medical costs. Liu Junqiang et al. (2015) believed that the main reason for the increase of medical expenses in China since 2003 was the increase of the utilization rate of medical services due to the promotion of medical insurance, while the micro basis was that the collusion of doctors and patients under the information asymmetry and the weak medical insurance supervision led to excessive medical treatment. The unbalanced allocation of medical and health resources is another prominent problem in the process of economic and social development in China. Zhu Ling (2000) takes the western development as an example to analyze the misunderstandings in the allocation of public resources, that is, the key to promoting regional development is to invest resources in the economic fields such as infrastructure construction, major projects on the horse, and ignore the investment in human resources, so it is difficult to achieve the coordinated development of regional economy and society. Lin et al. (2009) verified that the medical insurance of urban residents significantly promoted the utilization of medical services of urban residents when they were ill by using the data of "China urban residents basic medical insurance household survey (URBMI)". Huang Feng and Gan Li (2012) analyzed the data of China Health and Nutrition Survey (CHS) and found that the outpatient medical expenses of the employees with medical insurance were nearly twice as high as those of the uninsured, and the increase of the proportion of self payment could effectively reduce the medical expenses, but it did not affect the medical decision-making. Hu Hongwei et al. (2015) based on the data analysis of the national survey of the elderly, found that medical insurance has a significant role in promoting the use of health services for the elderly, and may improve the possibility of the elderly to overuse health services, and verified that the impact of insurance on the elderly's overuse of health services mainly occurs in cities and the elderly aged 60-80 years old. Lu Haixia (2009) thinks that there are great differences in the allocation of rural health resources between urban and rural areas in terms of capital allocation, health structure setting, and health personnel allocation. However, the lack of government leading functions, imperfect health organization system, insufficient and illiquid health human resources, and low economic affordability of rural health service objects result in the allocation of urban and rural health resources The important reason of balance. Feng Jin et al. (2015) from the perspective of the difference of medical expenditure for the elderly, investigated the rise of medical expenses caused by the difference of medical demand for the elderly in urban and rural areas, and suggested that the medical insurance system should adjust the allocation structure of medical resources according to the medical demand of the elderly while controlling the rise of total medical expenses. Therefore, a large number of literatures have confirmed the role of medical insurance in promoting medical expenses. On the one hand, medical insurance reduces the price of medical services and improves the affordability of medical service demanders, that is to say, income is an important factor affecting medical demand. Wang Xuanling (2005) thought that ideology, system and policy, medical security system are important factors that affect the fairness of medical and health allocation in China. Luo Chuliang (2008) used "China household income survey data (chips)" research to confirm that the medical expenses, whether borne by himself or reimbursed by medical insurance, increased with the increase of income level. Liu \& Zhao (2014) used 2006 and 2009 CHNS data to analyze the impact of urban residents' medical insurance on medical utilization and expenditure. They increased outpatient and inpatient use of urban pilot residents' medical care, but did not reduce out of pocket medical expenses. This medical insurance project improves the utilization of medical services for children, low-income families and residents in the relatively poor areas in the West.

China's medical reform still faces many problems, such as rising total medical costs, insufficient coverage of basic medical care and grass-roots medical construction, unstable foundation of 
basic drug system, unclear reform path of public hospitals, and ineffective long-term mechanism to promote the continuous progress of medical reform (Li Ling, 2012).

The effect of purchasing services has nothing to do with the ownership of medical service providers. According to Gu Xin (2012), the emergence and maturity of this "public contract model" is an integral part of global public management reform. This will transform the "command and control" mechanism into the "choice and competition" mechanism. In such a model, the government's financial expenditure is transformed from the supplier's appropriation to the government's purchase of services, while the service providers are moving towards diversified competition (Gu Xin, 2010). This kind of view is called "market faction" or "market leading faction" by the outside world. Different from what the name implies, this "faction" does not ignore the role of the government, but only emphasizes the importance of the decentralization and governance structure of the government and the market. The medical field has its particularity, so we must guarantee its public welfare "Geographic accessibility of medical services" (pigeon, Zhou Yinan, Fu Chen, et al. 2016) or spatial accessibility (Xie Hongmei, pan Jie. 2016), and there are also studies on the concept of directly using accessibility of health services (Wu Changling, Fang pengqian,2007; Xuzhou, Chen Jiaying,2008). Chenetal.(2007) evaluated the effectiveness of Taiwan's national health insurance program. They found that the health insurance program reduced the gap between different income groups in the use of medical resources, significantly increased the use of outpatient and inpatient services for the elderly, but this did not reduce mortality and produce better health self-assessment effect. Wagstaffetal. (2009) used data from the national public health and medical services survey panel to analyze the impact of NCMS.

Zhao Zhong and Huang Zhengang (2005) did not find any significant evidence that health insurance affects health by using China Health and nutrition survey data (CHNS). Xie Qian (2009) used CHNS data to find that the health status of high-income people was better and more medical services were used. They found that the NCMS increased the use of outpatient and inpatient services and reduced medical costs, but also did not reduce out of pocket expenses.

Cheng lingguo and Zhang Ye (2012) used the data of clhls in 2005 and 2008 to investigate the effect of NCMS on the performance of the elderly. They found that the NCMS significantly improved the health level of the participants, improved the status of "sick without medical treatment", improved the utilization rate of medical services, and reduced the proportion of out of pocket payment of the participants, but the actual medical expenditure and the incidence of serious illness expenditure did not decline significantly.

\section{METHODS}

Yang Bin (2009) used data envelopment analysis (DEA) to study the allocation efficiency of compulsory education resources in rural areas of China. He found that the allocation efficiency of compulsory education resources in rural areas of China was declining and there were differences between regions during the "Tenth Five Year Plan" period. The allocation efficiency of rural compulsory education resources in the eastern and central regions was generally higher than that in the western regions, and the allocation scale of rural compulsory education resources in the central region was more efficient in the eastern region And the West. Zhang jiluo (2013) found that since 2000, the number of years of education per capita in all provinces and regions has increased, the education Gini coefficient has generally decreased, and the education equity has improved. Lei \& Ling (2009) used didpmsm fixed effect tool variable method to analyze the impact of NCMS on medical utilization. The study found that the NCMS 
reduced the use of informal medical resources and increased the use of preventive medicine, especially general physical examination. But the NCMS did not reduce out of pocket spending.

Chen \& Jin (2010) used the data of China's 2006 agricultural census to investigate the effect of NCMS on infant mortality and maternal mortality at the age of 0-5. The original data showed that the addition of NCMS would reduce infant mortality and maternal mortality. However, after controlling the endogeneity of NCMS by the method of tendency matching, we found that NCMS had no effect on infant mortality and maternal mortality. Using Cobb Douglas production function model, sherry (2006) studied the effect of property insurance and life insurance on economic growth, and found that the former had a negative effect, while the latter had a positive effect on economic growth. Qian Zhen (2008) uses VAR model and impulse response function to analyze the long-term linkage effect of economic growth, residents' consumption and insurance development. The main results show that there is a dynamic co integration relationship among economic growth, household savings, consumption and insurance development. ZhuoZhi (19992001) used the statistical method of service economy to test the contribution of life insurance to China's economic growth.

Zeng Zhi, Yao Peng, et al. (2014) used the data of insurance market from 1999 to 2013, and ACE algorithm, and concluded that with the development of insurance market, the impact of insurance market on economic growth gradually increased; and there is an inverted U-shaped relationship with economic growth under different development levels, after market segmentation, it was found that non life insurance market has no significant growth effect on economic growth. Pangkai (2009) tested the role of property insurance and life insurance in China's economic growth by using the revised Solow model, and believed that the depth of property insurance has a significant positive impact on economic growth, while the depth of life insurance has no significant impact. In addition, compared with the independent influence of insurance and bank, the joint influence of insurance depth and bank loan ratio on economic growth is more significant. Liu Qinghui (2008) verified that insurance can promote endogenous economic growth by using the generation overlapping endogenous economic growth model. The author divided human savings into two types: one is liquid assets, the other is non liquid assets. He believed that insurance development has the effect of saving structure, which will lead to the relative increase of investment in non liquid assets, that is, it promotes the accumulation of capital and knowledge and form endogenous economic growth.

\section{RISK SOCIETY}

Baker pointed out that human beings are "on the volcano of civilization" and will have unforeseen consequences. Beck put forward the theory of risk society. Soon, the nuclear leakage accident of Chernobyl nuclear power plant shocked the world, which made people see the practical significance of the theory of risk society. With the development of society, the global financial crisis, political crisis, environmental crisis and military crisis make more risks appear. The concept of risk society is considered to form two schools, namely "realism risk view" and "constructivism risk view" (Pan bin, 2007). Most domestic scholars define risk from these two aspects. As far as emergencies are concerned, the "9.11" terrorist attacks, the prevalence of Sara and the blackout in the eastern United States indicate that there are various unpredictable "risk images" in the contemporary world (Huang Qingqiao, 2004). Yang Chunfu (2011) believes that risk society and social risk are different concepts, and the understanding of risk society must be placed in a specific context and field. Liu Yan and song Shuang (2005) analyzed the different ways of risk response of realism risk view and constructivism risk view. According to the view of realistic risk, "to control and avoid this kind of deep structural risk in modern society, we must rely on the creation of corresponding modern social structure. Chen Lei (2005) studied the relationship between the theory of risk society and the construction of a 
harmonious society, and proposed that the theory of risk society has guiding significance for the construction of a harmonious society. Because of the multiple risks, many scholars classify the risks. Yan Jinbao (2015) believes that the theory of risk society is of great significance to the improvement of social security system construction in China. With the deepening of the research on the theory of risk society in China, the concept of risk society has been fully recognized by the academic community and even the senior level of the ruling party of China. Social risk control, risk prediction and assessment, risk emergency management, risk source management, etc. have not only become a new concept and working concept, but also have entered the top level of the modernization of China's social governance system and governance capacity Therefore, the theory of risk society has considerable policy value for China's social transformation and development to cope with various risk challenges (Zhao Yandong, 2007).

\section{COMMENTS AND ENLIGHTENMENT}

Looking at the empirical research on the causal relationship between finance, insurance and economic growth, it is not difficult to find that scholars generally use the vector autoregressive model of time series for research, and their conclusions gradually change with the passage of time. Compared with the previous research conclusions, the later research tends to two-way causal research, which should be said that these research methods and results are We provide a good example. But at the same time, there are some questionable and further research areas. First, the application of cross-section data analysis method is based on the assumption of stable economic growth, but obviously the long-term economic growth of most countries is not stable. Second, domestic scholars have serious differences on the relationship between insurance and economic growth. The problems of resource allocation are mainly embodied in the problems of resource supply, demand and insurance, the problems of risk management, the problems of insurance products and the problems of resource mismatch. The existence of these problems stems from the influence of risk structure and social humanities, politics, economy, law and other factors on the allocation of insurance resources, from the imperfection of the insurance system and the lack of institutional innovation, which makes the insurance resources not fully and reasonably allocated, but also wastes the insurance resources in the existing allocation, and affects the value creation and sustainable development of the insurance industry.

\section{References}

Li Shuang. The impact of medical insurance on the happiness of the elderly [D]. Shandong University, 2018

Zhao Haofan. The impact of insurance agglomeration on regional economic growth [D]. Anhui University of Finance and economics, 2018

Xue Qiqi. Research on the effect of resource allocation and optimization of urban and rural endowment insurance [D]. Shandong University, 2018

Zhao Shangmei, Li Yong, Pang Yufeng. Theoretical model and empirical test of the contribution of insurance industry to economic growth [J]. Insurance research, 2009 (01): 51-56

Zhang Xiaoyan. Financial industry agglomeration and its impact on regional economic growth [D]. Shandong University, 2012

Li Xiangyu. Research on the path of China's insurance industry to promote economic growth [D]. Jilin University, 2012

Yu Changchun. Research on value creation mechanism of service modularization based on value chain [D]. Jiangxi University of Finance and economics, 2012

Wen Yang. Study on risk identification and assessment of large sports venues [D]. Shanghai Institute of physical education, 2012

PI Shuchu. Research on disaster loss compensation system from the perspective of risk society [D]. Wuhan University, 2013

Zhou Yuping. Research on China's health insurance system [D]. Wuhan University, 2013 
Wang Xinlan. Research on the effective demand of policy based agricultural insurance in China [D]. Liaoning University, 2013

Xing Tingting. Research on internal control of insurance companies [D]. Nankai University, 2013

Li Xiaoyu. Empirical Study on the efficiency of insurance fund utilization [D]. Capital University of economics and trade, 2014

Dong Jianguo. Comparative study on the efficiency of insurance industry between China and Russia [D]. Shandong University, 2014

Shi Peiqin. Research on Equalization of regional basic public services in China [D]. Institute of financial science, Ministry of finance, 2014

Wang yinglei. Research on the transformation and development of China's official export credit and its institutions [D]. Institute of financial science, Ministry of finance, 2014

Hu Ying. Research on the effective supply, efficiency and risk of China's insurance industry [D]. Jinan University, 2008

Du Shilin. Research on the legal system of medical and health resources allocation [D]. Southwest University of political science and law, 2008

Yang panyong. Research on risk management and control of insurance fund utilization [D]. Tianjin University, 2007

Zhang Qin. Research on comprehensive risk management of insurance companies based on value creation [D]. Nankai University, 2009

Wan Qingyao. Research on supply and demand of insurance services and value creation in China [D]. Southwest University of Finance and economics, 2010

fan Lijun. Research on the mechanism of value creation through cooperation of value network enterprises based on resource sharing [D]. Zhejiang University, 2011

Yao Shujie, Feng Genfu, Han Zhongwei. Empirical analysis of the efficiency of China's insurance industry [J]. Economic research, 2005 (07): 56-65

Xiao Feng. Economic analysis of optimal allocation of medical and health resources in China [J]. Economic Research Guide, 2018 (06): 177-178

Liu Jun. overall resource allocation is conducive to improving the public service quality of medical insurance [J]. China medical insurance, 2018 (07): 18-19

Zhang Li, Zhang Xiumin, Wu Fangyuan, Li Xuanxuan, Ma Juan. Current situation and influencing factors of nurse resource allocation in Changchun pension institutions [J]. Medicine and society, 2018,31 (07): 81-83

he wenjiong. On the optimal allocation of social security resources in China [J]. Social security review, 2018,2 (04): 3-13

Sun Rong. Government and market in insurance resource allocation [J]. Insurance research, 2008 (05): 17-20

Wang Jiangang. Pareto optimization of social endowment insurance resources allocation [J]. Population and economy, 2002 (01): 69-74

Li min. study on the allocation of urban and rural medical and health resources in Shanxi Province [D]. Shanxi University of Finance and economics, 2012

Han Shengxi, Ye Lu. Analysis of the effect of medical insurance payment system on the allocation of health resources [J]. Health soft science, 2013,27 (06): 340-342

Zhao Yun. Medical insurance and transformation of allocation mechanism of primary medical and health resources [J]. Medicine and Philosophy (a), 2014, 35 (11): 40-43 + 81

Sun Rong. On the allocation of commercial insurance resources in China -- mechanism design and policy analysis [D]. Southwest University of Finance and economics, 2004

Liu Jiyang. Ethical research on fair allocation of public health resources [D]. Central South University, 2008

Chen Xiaoan. Research on social responsibility of insurance companies from the perspective of resource allocation [J]. Journal of Hubei University of economics, 2011,9 (03): 107-112

Li Wenjing. Study on the mechanism of optimizing the allocation of insurance resources [D]. University of foreign economic and trade, 2006 
Zhang Xufeng. On the value and value creation of insurance products [J]. Insurance research, 2007 (02): 68-70

Li Wanlian, Zhou Siyu, Yu Yong. Medical and health security, allocation of health resources and medical selection of rural labor force based on data analysis of 2016clds [J]. Hunan Social Sciences, 2019 (01): 81-87

Khoo Joanna,Hasan Helen,Eagar Kathy. Examining the high users of hospital resources: implications of a profile developed from Australian health insurance claims data.[J]. Australian health review : a publication of the Australian Hospital Association,2017.

Ma Weiling. Justice Research on urban health resource allocation [D]. Suzhou University, 2017

Yao-Chun Hsu. Analyzing Taiwan's National Health Insurance Research Database to explicate the allocation of health-care resources[J]. Advances in Digestive Medicine,2015,2(2).

L. Wen,J. Wu,L. Yang. Medical resource Utilization of Ischemic Stroke Patients with readmission: a retrospective analysis of Hospitalization data from Beijing Medical Insurance database[J]. Value in Health,2015,18(3).

Kreng Victor,Yang Shao-wei. Efficiency of resource allocation in the hospital sector after global budgeting under National Health Insurance.[J]. Chinese medical journal,2013,126(15). 